\title{
Donepezil for the Treatment of Agitation in Alzheimer's Disease
}

\author{
Robert J. Howard, M.R.C.Psych., Edmund Juszczak, B.Sc., \\ Clive G. Ballard, M.R.C.Psych., Peter Bentham, M.R.C.Psych., \\ Richard G. Brown, Ph.D., Roger Bullock, M.R.C.Psych., \\ Alistair S. Burns, F.R.C.Psych., Clive Holmes, M.R.C.Psych., \\ Robin Jacoby, F.R.C.Psych., Tony Johnson, Ph.D., Martin Knapp, Ph.D., \\ James Lindesay, F.R.C.Psych., John T. O'Brien, F.R.C.Psych., \\ Gordon Wilcock, F.R.C.P., Cornelius Katona, F.R.C.Psych., Roy W. Jones, F.R.C.P., \\ Julia DeCesare, B.A., and Michaela Rodger, for the CALM-AD Trial Group*
}

From the Medical Research Council (MRC) Neurogeneration Research Centre, Institute of Psychiatry, King's College London, London (R.J.H.); the Centre for Statistics in Medicine, Wolfson College, Oxford (E.J.); the Wolfson Centre for Age Related Disease, King's College London, London (C.G.B.); the Queen Elizabeth Psychiatric Hospital, Birmingham (P.B.); the Institute of Psychiatry, King's College London, London (R.G.B., M.K.); Victoria Hospital, Swindon (R.B.); the Division of Psychiatry, Manchester University, Manchester (A.S.B.); the Memory Assessment and Research Centre, University of Southampton, Southampton (C.H.); the Department of Psychiatry, University of Oxford, Oxford (R.J.); the MRC Biostatistics Unit, University of Cambridge Institute of Public Health, Cambridge (T.J.); the Department of Health Sciences, University of Leicester, Leicester (J.L.); the Institute for Ageing and Health, Newcastle University, Newcastle (J.T.O.); the Nuffield Department of Medicine, John Radcliffe Hospital, Oxford (G.W.); the Kent Institute of Medicine and Health, University of Kent, Canterbury (C.K.); the Research Institute for the Care of the Elderly, Bath (R.W.J.); and the Section of Old Age Psychiatry, Institute of Psychiatry, King's College London, London (J.D., M.R.) - all in the United Kingdom. Address reprint requests to Prof. Howard at the Medical Research Council Centre for Neurodegeneration Research, Institute of Psychiatry, King's College London, DeCrespigny Park, London SE5 8AF, United Kingdom, or at robert.howard@iop.kcl.ac.uk.

*Investigators and committees of the Trial of a Cholinesterase Inhibitor and Atypical Neuroleptic in the Management of Agitation in Alzheimer's Disease (CALM-AD) are listed in the Appendix.

N Engl J Med 2007;357:1382-92.

Copyright (c) 2007 Massachusetts Medical Society.

\section{ABSTRACT}

\section{BACKGROUND}

Agitation is a common and distressing symptom in patients with Alzheimer's disease. Cholinesterase inhibitors improve cognitive outcomes in such patients, but the benefits of these drugs for behavioral disturbances are unclear.

\section{METHODS}

We randomly assigned 272 patients with Alzheimer's disease who had clinically significant agitation and no response to a brief psychosocial treatment program to receive $10 \mathrm{mg}$ of donepezil per day (128 patients) or placebo (131 patients) for 12 weeks. The primary outcome was a change in the score on the Cohen-Mansfield Agitation Inventory (CMAI) (on a scale of 29 to 203, with higher scores indicating more agitation) at 12 weeks.

\section{RESULTS}

There was no significant difference between the effects of donepezil and those of placebo on the basis of the change in CMAI scores from baseline to 12 weeks (estimated mean difference in change [the value for donepezil minus that for placebo], -0.06 ; $95 \%$ confidence interval [CI], -4.35 to 4.22$)$. Twenty-two of 108 patients (20.4\%) in the placebo group and 22 of 113 (19.5\%) in the donepezil group had a reduction of 30\% or greater in the CMAI score (the value for donepezil minus that for placebo, -0.9 percentage point; $95 \%$ CI, -11.4 to 9.6). There were also no significant differences between the placebo and donepezil groups in scores for the Neuropsychiatric Inventory, the Neuropsychiatric Inventory Caregiver Distress Scale, or the Clinician's Global Impression of Change.

\section{CONCLUSIONS}

In this 12 -week trial, donepezil was not more effective than placebo in treating agitation in patients with Alzheimer's disease. (ClinicalTrials.gov number, NCT00142324.) 
LZHEIMER'S DISEASE CAUSES A PROGRESsive decline in cognitive and functional ability and distress on the part of both patients and their caregivers. Agitation, a cluster of related symptoms that includes anxiety, irritability, and motor restlessness, leading to behaviors such as pacing, wandering, shouting, and aggression, ${ }^{1}$ is seen in $24 \%$ of people with Alzheimer's disease who live in the community ${ }^{2}$ and in $48 \%$ of those living in residential care facilities. ${ }^{3}$ Behavioral and psychological symptoms in Alzheimer's disease are distressing to caregivers ${ }^{4,5}$ and often precipitate the transition to residential care. ${ }^{6}$ Atypical neuroleptic agents remain the mainstay of drug treatment despite only modest short-term effica$\mathrm{cy}^{7,8}$ and serious side effects, including stroke and death. ${ }^{9}$

Trial data suggest a reduced emergence of behavioral and psychiatric symptoms in patients treated with cholinesterase inhibitors ${ }^{10}$; these data also suggest improvements in scores on the Neuropsychiatric Inventory (NPI) ${ }^{11}$ in patients with behavioral disturbances who continue treatment as compared with those in whom treatment is withdrawn. ${ }^{12}$ A systematic review and meta-analysis $^{13}$ concluded that cholinesterase inhibitors have modest beneficial effects on neuropsychiatric symptoms, with a reduction of 1.72 points $(95 \%$ confidence interval [CI], 0.087 to 2.57 ) on the NPI (on a scale of 1 to 144, with lower scores indicating less frequent or severe symptoms). A Cochrane review ${ }^{14}$ concluded that treatment was associated with a reduction of 2.44 points ( $95 \%$ CI, 0.76 to 4.12). A post hoc analysis of pooled behavioral data from three large galantamine trials showed modest but significant improvements in the total NPI score and in the subscales for agitation or aggression, anxiety, disinhibition, and aberrant motor behavior. ${ }^{15}$ Finally, a small study reported a nonsignificant advantage of rivastigmine over placebo with respect to the score on the Cohen-Mansfield Agitation Inventory (CMAI). ${ }^{16,17}$

Clinical uncertainty persists regarding the efficacy of cholinesterase inhibitors when behavioral disturbance is severe and is the indication for treatment. We conducted a study to assess the effect of 12 weeks of treatment with donepezil (Aricept, Janssen) on clinically significant agitation in patients with Alzheimer's disease. Because best practice involves an initial trial of a nonpharmacologic approach ${ }^{1}$ and previous studies have shown a rate of response to placebo in excess of $40 \%,{ }^{18}$ we enrolled only those patients whose agitation was so severe that it was clinically necessary for them to receive drug treatment and whose agitation failed to respond to a 4-week psychosocial treatment. The primary question was whether donepezil is better than placebo in the management of agitation that is inappropriate for, or has not responded to, a psychosocial treatment.

\section{METHODS}

The original study was a multicenter, blinded, randomized, parallel-group trial in which patients were assigned to receive risperidone (Rispendal, Eisai), donepezil, or placebo for 12 weeks, after 4 weeks of psychosocial treatment. The target sample size was 285 people with Alzheimer's disease. Recruitment started in November 2003 but was suspended in March 2004, following the recommendation by the United Kingdom Committee for Safety of Medicines that risperidone and olanzapine not be used for the treatment of behavioral symptoms in dementia. ${ }^{19}$ The trial was restarted in July 2004 with a two-group design (donepezil and placebo), and recruitment ended in September 2005.

\section{PARTICIPANTS}

Patients were recruited at eight clinical centers in England. They were eligible for inclusion if they met the diagnostic criteria of the National Institute of Neurological and Communication Disorders and Stroke-Alzheimer's Disease and Related Disorders Association ${ }^{20}$ for probable or possible Alzheimer's disease; had clinical agitation (causing distress to the patient and at least moderate management problems for caregivers on at least 2 days per week for a 2-week period, together with a $\mathrm{CMAI}^{16}$ score of 39 or more, on a scale from 29 to 203, with higher scores indicating more frequent or severe agitation); were older than 39 years of age; lived in a residential care facility or with a caregiver in the community; were not receiving neuroleptic agents or cholinesterase inhibitors at the time of enrollment, had not received them in the previous 4 weeks, and were not being considered for such treatment for the next 16 weeks; had the capacity and were willing to consent to participation in the study or lacked the capacity and assented to participation; and had a caregiver who was in agreement with the patient's assent to participate. 
Written informed consent was obtained from patients when it could be given, and written assent was obtained from all caregivers for the patients' involvement in the trial. Exclusion criteria were a known sensitivity to donepezil; severe, unstable, or uncontrolled medical conditions; delirium; dementia with Lewy bodies ${ }^{21}$; and evidence of poor compliance with prescribed medication.

\section{INTERVENTIONS}

Before randomization, patients participated in a psychosocial treatment program for up to 4 weeks, consisting of four sessions (two in person and two conducted by telephone) during which the main caregiver was trained to deliver one of three treatment options - standardized social interaction, personalized music, or removal of triggers for agitated behaviors ${ }^{22}$ - selected on the basis of an assessment during the first session. Patients whose CMAI score was 39 or more after the psychosocial treatment were enrolled in the drug-treatment phase of the study and randomly assigned to receive donepezil or placebo daily for 12 weeks. Patients whose agitation was considered sufficiently severe to merit immediate drug treatment could enter the randomized phase immediately, and those who started psychosocial treatment but whose agitation was judged clinically not to have responded could enter the randomized phase before completion of psychosocial treatment.

Trial medication was encapsulated. Clinicians, those administering the trial medication, patients, caregivers, and outcome assessors were all unaware of the treatment assignments. During weeks 1 through 4 of the trial, patients received one capsule (5 mg of donepezil or placebo) daily. During weeks 5 through 12, patients received two capsules (10 mg of donepezil or placebo) daily. At the end of week 12, decisions about treatment of agitation were the responsibility of the referring physician.

\section{OUTCOME MEASURES}

The total CMAI score at 12 weeks was designated as the primary outcome. Secondary outcomes included the caregiver's assessments of symptoms with the NPI, ${ }^{11}$ either the NPI Nursing Home Ver$\operatorname{sion}^{23}$ or the NPI Caregiver Distress Scale (depending on whether the patient was living in a nursing home or at home), ${ }^{24}$ and cognitive function as measured with the Severe Impairment Battery (SIB), ${ }^{25}$ the Standardized Mini-Mental State Examination
(SMMSE), ${ }^{26}$ and the Clinician's Global Impression of Change (CGIC). ${ }^{27}$

Outcomes assessors were psychologists or registered nurses who attended a week-long training course designed to familiarize them with the instruments and standardize delivery. To assess the adequacy and consistency of delivery of the psychosocial treatment, $10 \%$ of the sessions were videotaped and rated.

\section{EVALUATIONS}

There were four assessment points. Before psychosocial treatment, consent was obtained, and the CMAI, SMMSE, and NPI Caregiver Distress Scale were administered. Before enrollment in the drug trial, the CMAI, NPI, and SMMSE were administered; those patients with CMAI scores of 39 or higher were enrolled in the trial and underwent randomization, and the SIB, CGIC, and NPI Caregiver Distress Scale were administered. At week 4 (the time of dose escalation), the CMAI, NPI, and NPI Caregiver Distress Scale were administered. At week 12 (the end of the trial), the CMAI, NPI, SMMSE, SIB, CGIC, and NPI Caregiver Distress Scale were administered.

Adverse events were reported immediately to local principal investigators, who decided whether the assigned treatment should be revealed or the patient removed from the trial. Written report forms were faxed to the central trial office and submitted monthly to the chair of the Data Monitoring and Ethics Committee.

\section{RANDOMIZATION}

Telephone randomization was performed centrally by the Medical Research Council (MRC) Clinical Trials Unit. Assignment of treatment to drug-pack numbers was performed with the use of a random sequence of numbers (fixed blocks of six). The list of treatment assignments was checked and approved by trial statisticians.

The data manager determined treatment assignments using a fully blind minimization algorithm containing an embedded list of pack numbers with corresponding treatment. The first 20 patients were assigned by means of simple randomization with the use of a prepared list. For the rest of the patients, a minimization method was used to balance treatment assignments according to four stratifying factors: participating center, age (40 to 59 years, 60 to 74 years, or $\geq 75$ years), 


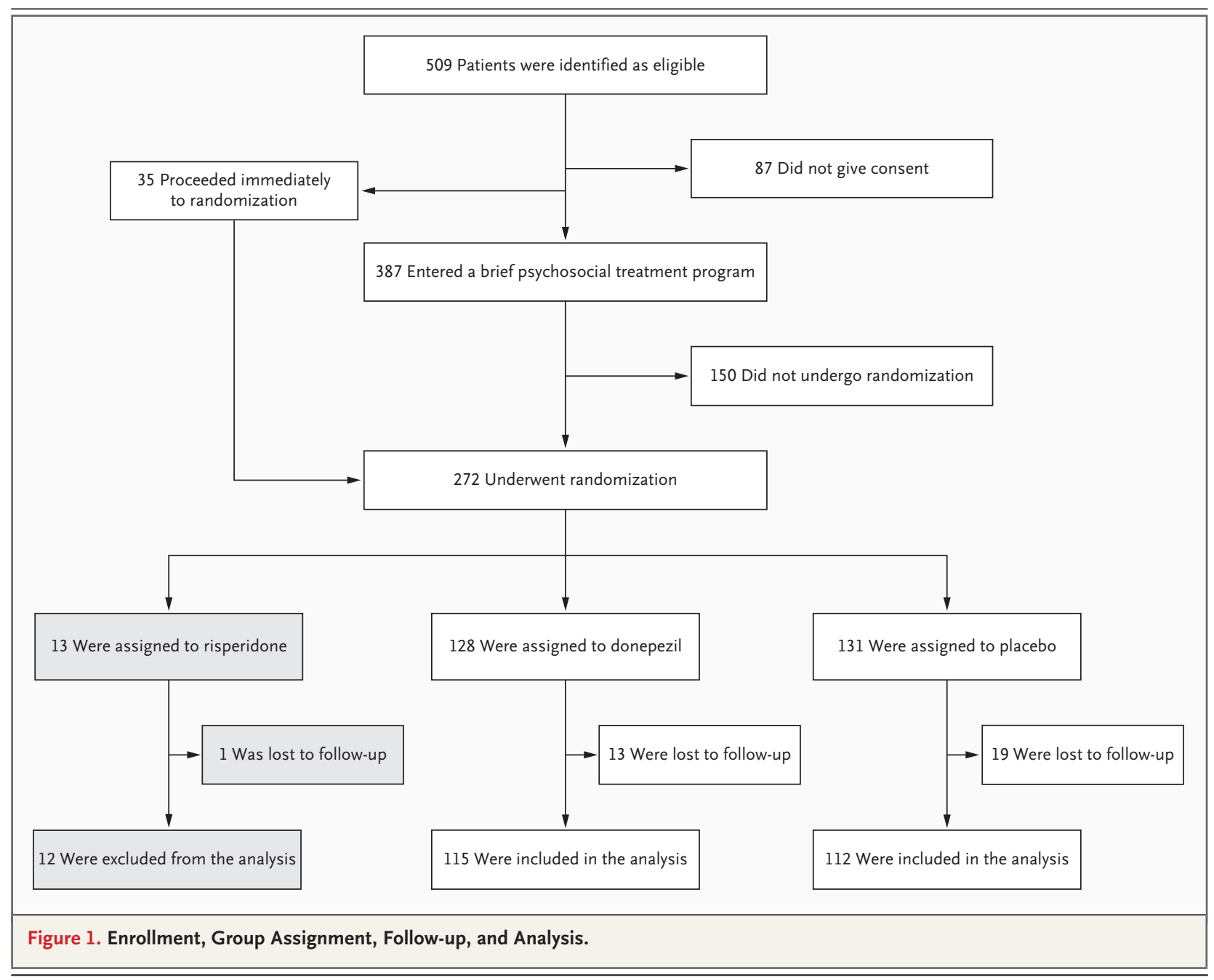

psychosocial treatment (no treatment, incomplete treatment $[<4$ weeks], or complete treatment [ 4 weeks]), and place of residence (own or relative's home, residential care facility, or other). The minimization algorithm summed previous treatment assignments across the four strata, matching the new patient and using probability ratios of 0.75 and 0.25 to assign treatment, with the higher ratio (0.75) applied to the treatment with the lower total.

When a patient was to undergo randomization, physicians at the center completed the Patient Entry and Randomization Checklist, obtained the patient's consent to randomization, and then telephoned the data manager at the MRC, who determined the number of the drug pack to be assigned and informed the pharmacist at the participating center. The pharmacist then dispensed the appropriate drug pack to local research staff, ensuring concealment.

\section{STATISTICAL ANALYSIS}

We prespecified a clinically important response as a $30 \%$ or greater reduction in agitation ${ }^{18}$ and anticipated that the rate of response to placebo would be $30 \%$ and the rate of response to risperidone or donepezil would be approximately $55 \%$. To detect a difference of 25 percentage points between response rates with active treatment and placebo, with $90 \%$ power at the $5 \%$ level of significance, 81 participants would be required in each group; with a $15 \%$ dropout rate, 95 participants would be required in each group.

We used SPSS for Windows (version 12.0.1) to 


\begin{tabular}{|c|c|c|c|}
\hline Characteristic & $\begin{array}{c}\text { Placebo } \\
(\mathrm{N}=131)\end{array}$ & $\begin{array}{l}\text { Donepezil } \\
(\mathrm{N}=128)\end{array}$ & $P$ Value \\
\hline Age $-y r$ & & & 0.83 \\
\hline Mean & $84.4 \pm 8.2$ & $84.9 \pm 7.3$ & \\
\hline Median & 85.1 & 85.1 & \\
\hline Interquartile range & 79.9-90.2 & $80.1-90.4$ & \\
\hline Total CMAI score & & & 0.34 \\
\hline Mean & $60.7 \pm 16.5$ & $62.5 \pm 17.5$ & \\
\hline Median & 57.0 & 59.5 & \\
\hline Interquartile range & $47.0-72.0$ & $50.0-71.5$ & \\
\hline CGIC score & & & 0.42 \\
\hline Mean & $4.3 \pm 1.1$ & $4.2 \pm 1.1$ & \\
\hline Median & 4.0 & 4.0 & \\
\hline Interquartile range & $4.0-5.0$ & $3.0-5.0$ & \\
\hline Missing data — no. & 7 & 4 & \\
\hline Total NPI score & & & 0.70 \\
\hline Mean & $23.6 \pm 16.7$ & $23.7 \pm 15.9$ & \\
\hline Median & 20.0 & 23.0 & \\
\hline Interquartile range & $12.0-33.0$ & $11.0-32.0$ & \\
\hline Missing data — no. & 7 & 1 & \\
\hline Total score on NPI Caregiver Distress Scale & & & 0.22 \\
\hline Mean & $7.3 \pm 7.8$ & $8.0 \pm 7.5$ & \\
\hline Median & 5.0 & 6.0 & \\
\hline Interquartile range & $1.0-10.0$ & $2.0-12.0$ & \\
\hline Missing data - no. & 7 & 1 & \\
\hline Total SIB score & & & 0.49 \\
\hline Mean & $55.9 \pm 34.9$ & $53.8 \pm 32.0$ & \\
\hline Median & 67.5 & 60.0 & \\
\hline Interquartile range & $22.0-88.0$ & $26.0-83.0$ & \\
\hline Missing data - no. & 45 & 40 & \\
\hline Total SMMSE score & & & 0.82 \\
\hline Mean & $8.2 \pm 6.8$ & $8.1 \pm 5.9$ & \\
\hline Median & 8.0 & 8.0 & \\
\hline Interquartile range & $2.0-14.0$ & $3.0-12.0$ & \\
\hline Missing data - no. & 36 & 44 & \\
\hline
\end{tabular}

manage data and Stata (version 9.2) for analyses. Demographic and clinical characteristics were summarized by using counts and percentages for categorical variables, means \pm SD for normally distributed continuous variables, and medians with interquartile ranges for non-normally distributed continuous variables.
Comparative analyses were restricted to patients who were assigned to the donepezil and placebo groups. Specifically, patients were analyzed in the groups to which they were assigned. Primary analysis was performed for patients with complete data at both baseline and week 12, including those who did not adhere to the protocol 


\begin{tabular}{|c|c|c|c|}
\hline \multicolumn{4}{|l|}{ Table 1. (Continued.) } \\
\hline Characteristic & $\begin{array}{l}\text { Placebo } \\
(\mathrm{N}=131)\end{array}$ & $\begin{array}{l}\text { Donepezil } \\
(\mathrm{N}=128)\end{array}$ & P Value \\
\hline Female sex - no. (\%) & $114(87.0)$ & $105(82.0)$ & 0.27 \\
\hline Race - no. (\%)† & & & 0.41 \\
\hline White & $126(96.2)$ & $126(98.4)$ & \\
\hline Black & $4(3.1)$ & $1(0.8)$ & \\
\hline Missing data & $1(0.8)$ & $1(0.8)$ & \\
\hline Regular use of stable dose of psychotropic agents at trial entry — no. $(\%) \ddagger$ & $18(13.8)$ & $33(25.8)$ & 0.02 \\
\hline Place of residence - no. (\%) & & & 0.68 \\
\hline Own or relative's home & $7(5.3)$ & $4(3.1)$ & \\
\hline Residential care facility & $121(92.4)$ & $121(94.5)$ & \\
\hline Other & $3(2.3)$ & $3(2.3)$ & \\
\hline Brief psychosocial treatment — no. (\%) & & & 0.94 \\
\hline None & $18(13.7)$ & $16(12.5)$ & \\
\hline Incomplete (<4 wk) & $11(8.4)$ & $10(7.8)$ & \\
\hline Complete (4 wk) & 102 (77.9) & 102 (79.7) & \\
\hline \multicolumn{4}{|l|}{ Relationship of informant to patient at randomization - no. (\%)』 } \\
\hline Professional caregiver & $119(90.8)$ & $123(96.1)$ & 0.12 \\
\hline Spouse & $1(0.8)$ & $3(2.3)$ & \\
\hline Child & $5(3.8)$ & - & \\
\hline Sibling & $1(0.8)$ & - & \\
\hline Other & $1(0.8)$ & - & \\
\hline Missing data & $4(3.0)$ & $2(1.6)$ & \\
\hline
\end{tabular}

* Plus-minus values are means \pm SD. CMAI denotes Cohen-Mansfield Agitation Inventory, which includes 29 items. Scores range from 29 to 203, with higher scores indicating more frequent or severe agitation. Scores above 40 are usually considered to be clinically significant. CGIC denotes Clinician's Global Impression of Change, which has a single item. Scores range from 1 to 7, with higher scores indicating greater impairment. NPI denotes Neuropsychiatric Inventory, which has 12 domains, including neurovegetative signs (preceding 2 weeks). Scores range from 1 to 144, with lower scores indicating less frequent or severe symptoms and signs. The NPI Caregiver Distress Scale has 12 domains (NPI Nursing Home Version used if the patient lived in a nursing home). Scores range from 0 to 60 , with lower scores indicating less distress. SIB denotes Severe Impairment Battery, which includes 51 items. Scores range from 0 to 100 , with higher scores indicating better performance. SMMSE denotes Standardized Mini-Mental State Examination, which includes 12 questions. Scores range from 0 to 30 , with higher scores indicating better performance.

$\uparrow$ Race was reported by physicians.

$\Varangle$ Psychotropic agents taken included benzodiazepine or other nighttime sedating medication, sedative antidepressant agents, mood-stabilizing medication, and other neuroleptic agents.

$\int A t 12$ weeks, on study completion, the relationship of the informant to the patient was the same in all but two cases (one professional caregiver was replaced by the patient's child, and one sibling was replaced by a professional caregiver).

(e.g., those who never started treatment but for whom we had complete data). For the primary analysis, the change in the CMAI score from baseline to 12 weeks was summarized as the mean $( \pm \mathrm{SD})$ change among patients with complete data at both baseline and 12 weeks. To establish the magnitude and direction of the treatment effect, the change in the CMAI score from baseline to 12 weeks in the donepezil group was compared with the change in the placebo group by means of analysis of covariance (ANCOVA), and the results were expressed as the difference (plus $95 \%$ confidence interval), with adjustment for the baseline value. An additional ANCOVA was performed with adjustment for the four stratification factors, as well as time and the baseline value. Changes in secondary outcomes were summarized and compared in a similar fashion.

The treatment response was assessed by calculating the difference between groups in the 


\begin{tabular}{|c|c|c|c|c|c|c|}
\hline Assessment & Placebo & Donepezil & $\begin{array}{l}\text { Adjusted for } \\
\text { Baseline Value }\end{array}$ & $\begin{array}{c}\text { Adjusted for } \\
\text { Baseline Value and } \\
\text { Stratification Factors }\end{array}$ & $\begin{array}{l}\text { Adjusted for } \\
\text { Baseline Value }\end{array}$ & $\begin{array}{c}\text { Adjusted for } \\
\text { Baseline Value } \\
\text { and Stratification } \\
\text { Factors }\end{array}$ \\
\hline No. of patients (\%) & $108(82)$ & $113(88)$ & & & & \\
\hline Score & $4.99 \pm 18.98$ & $6.34 \pm 20.35$ & $-0.064(-4.35$ to 4.22$)$ & $0.18(-4.22$ to 4.59$)$ & 0.98 & 0.94 \\
\hline \multicolumn{7}{|l|}{ NPI (all 12 items) } \\
\hline No. of patients (\%) & $97(74)$ & $104(81)$ & & & & \\
\hline Score & $1.29 \pm 7.65$ & $1.53 \pm 7.44$ & $-0.20(-1.86$ to 1.47$)$ & $-0.45(-2.06$ to 1.15$)$ & 0.82 & 0.58 \\
\hline \multicolumn{7}{|l|}{ SIB (all 51 items) } \\
\hline No. of patients (\%) & $33(25)$ & $27(21)$ & & & & \\
\hline Score & $-4.82 \pm 8.80$ & $1.93 \pm 11.14$ & 6.45 (1.07 to 11.83$)$ & 7.26 (1.27 to 13.26$)$ & 0.02 & 0.02 \\
\hline \multicolumn{7}{|l|}{ SMMSE (all 20 items) } \\
\hline No. of patients (\%) & $57(44)$ & $56(44)$ & & & & \\
\hline Score & $-0.96 \pm 3.86$ & $0.54 \pm 3.47$ & 1.55 (0.23 to 2.88$)$ & 1.49 (0.14 to 2.84$)$ & 0.02 & 0.03 \\
\hline
\end{tabular}

* Plus-minus values are means \pm SD. Analysis of covariance (ANCOVA) was adjusted for baseline measurement. Stratification factors were center (8 categories), age (continuous variable), participation in psychosocial treatment (none, incomplete $[<4$ weeks], or complete $[4$ weeks]), and place of residence (own or relative's home, residential care facility, or other), plus number of study groups at time of enrollment (three or two). CMAI denotes Cohen-Mansfield Agitation Inventory, which includes 29 items. Scores range from 29 to 203 , with higher scores indicating more frequent or severe agitation. Scores above 40 are usually considered to be clinically significant. NPI denotes Neuropsychiatric Inventory, which has 12 domains, including neurovegetative signs (preceding 2 weeks). Scores range from 1 to 144 , with lower scores indicating less frequent or severe symptoms and signs. The NPI Caregiver Distress Scale has 12 domains. Scores range from 0 to 60 , with lower scores indicating less distress. SIB denotes Severe Impairment Battery, which includes 51 items. Scores range from 0 to 100 , with higher scores indicating better performance. SMMSE denotes Standardized Mini-Mental State Examination, which includes 12 questions. Scores range from 0 to 30 , with higher scores indicating better performance.

$\uparrow$ Positive change represents improvement.

$\neq$ Placebo is the reference group; a positive difference favors donepezil.

proportion of patients with more than a $30 \%$ reduction in agitation ( $95 \%$ confidence interval). Sensitivity analyses were carried out to examine the robustness of the results with different assumptions about departures from randomization policies, depending on the availability of data and the particular set of circumstances (see the Supplementary Appendix, available with the full text of this article at www.nejm.org).

The authors designed the study, site investigators gathered the data, trial statisticians carried out the analyses, and the authors wrote the manuscript and vouch for the completeness and accuracy of the data and analyses. The companies that donated the medications had no role in the trial design, data accrual, data analysis, or preparation of the manuscript.

\section{RESULTS}

Between November 2003 and December 2005, a total of 509 patients were identified as eligible; $87(17.1 \%)$ did not give consent for inclusion. Thirty-five patients proceeded immediately to randomization. Of the 387 patients who entered the psychosocial-treatment phase, 53 (13.7\%) had improvement to the degree that their CMAI score fell below the threshold required to proceed to randomization. Video and written records showed that $93 \%$ of psychosocial treatment sessions followed the procedures as demonstrated during training.

Of the 272 patients who underwent randomization between November 2003 and December 2005, a total of $262(96.3 \%)$ received a drug or placebo (12 received risperidone, 124 donepezil, and 126 
placebo) (Fig. 1). Among the 250 patients assigned to receive donepezil or placebo, CMAI assessments were completed for $100 \%$ at baseline and for $90.8 \%$ (227 of 250) at 12 weeks, with all four CMAI assessments completed for 221 of 227 patients (113 in the donepezil group and 108 in the placebo group).

Demographic characteristics and the stage of dementia were similar in the two groups (Table 1); the groups were slightly imbalanced in terms of the proportion of patients regularly taking any stable dose of psychotropic agents at trial entry, but the treatment effect was similar in patients who were taking such agents at baseline and those who were not $(\mathrm{P}=0.51$ for the test of an interaction).

\section{PRIMARY OUTCOME}

The estimated mean reduction in the CMAI score from baseline to 12 weeks did not differ significantly between the placebo and donepezil groups (Table 2 and Fig. 2); the average change in the score was $4.99 \pm 18.98$ points in the placebo group and $6.34 \pm 20.35$ points in the donepezil group. With adjustment for the baseline value, the estimated difference in the reduction from baseline (the value for donepezil minus that for placebo) was -0.06 (95\% CI, -4.35 to 4.22 ).

The proportion of patients with a response to treatment (defined as a $30 \%$ or greater reduction in the total CMAI score from baseline to 12 weeks) was similar in the two groups -22 of 108 patients (20.4\%) in the placebo group and 22 of 113 (19.5\%) in the donepezil group (difference in treatment response [the value for donepezil minus that for placebo], -0.9 percentage point; $95 \% \mathrm{CI},-11.4$ to 9.6).

\section{SECONDARY OUTCOMES}

The reduction in the NPI score from baseline to 12 weeks did not differ significantly between the placebo and donepezil groups (Table 2); the mean reduction was $3.78 \pm 17.75$ points for the placebo group and $3.56 \pm 17.73$ points for the donepezil group. With adjustment for the baseline value, the estimated difference in reduction between the two groups was -0.13 (95\% CI, -4.06 to 3.80). Similarly, scores on the NPI Caregiver Distress Scale (which range from 0 to 60, with lower scores indicating less distress) improved in both groups, with a mean reduction of $1.29 \pm 7.65$ points in the placebo group and $1.53 \pm 7.44$ points in the donepezil group. With adjustment for the baseline value, the esti-

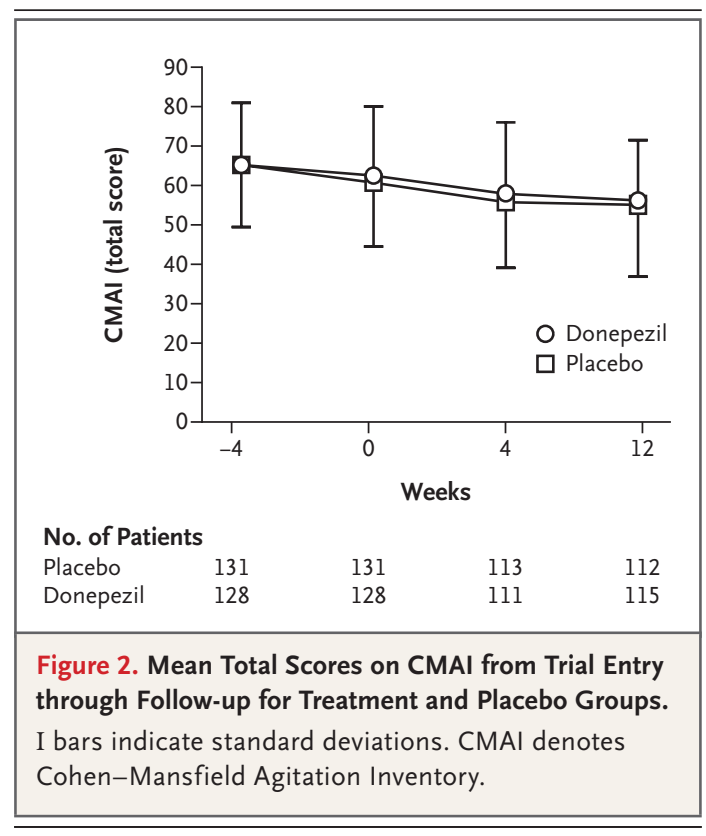

mated difference in reduction between the groups was -0.20 ( $95 \% \mathrm{CI},-1.86$ to 1.47 ).

Mean follow-up values for the CGIC (on which scores range from 1 to 7 , with higher scores indicating greater impairment) were $3.93 \pm 1.08$ for the placebo group and $3.87 \pm 1.25$ for the donepezil group. With adjustment for the baseline CGIC score, the estimated mean difference in the change from baseline between the two groups was -0.06 ( $95 \%$ CI, -0.37 to 0.25 ) in favor of the placebo group.

For the SIB (scores range from 0 to 100, with higher scores indicating better performance), patients receiving donepezil increased their score by $1.93 \pm 11.14$ points as compared with a decrease in the placebo group of $4.82 \pm 8.80$ points. With adjustment for the baseline value, the estimated mean difference between groups in the change from baseline was 6.45 (95\% CI, 1.07 to 11.83), indicating greater cognitive deterioration in the placebo group $(\mathrm{P}=0.02)$. However, the proportion of patients fully able to complete the SIB was $25 \%$ in the placebo group and only $21 \%$ in the donepezil group.

Similarly, patients receiving donepezil had an estimated mean increase in the SMMSE score (scores range from 0 to 30, with higher scores indicating better performance) from baseline to 12 weeks of $0.54 \pm 3.47$ points as compared with a mean decrease of $0.96 \pm 3.86$ points in the placebo group. With adjustment for the baseline value, the estimated difference in the change from baseline 


\begin{tabular}{|c|c|c|c|}
\hline \multirow[t]{2}{*}{ Adverse Event } & $\begin{array}{c}\text { Psychosocial } \\
\text { Treatment } \\
(\mathrm{N}=422)\end{array}$ & $\begin{array}{c}\text { Donepezil } \\
(\mathrm{N}=128)\end{array}$ & $\begin{array}{c}\text { Placebo } \\
(\mathrm{N}=131)\end{array}$ \\
\hline & \multicolumn{3}{|c|}{ number (percent) } \\
\hline Nausea, vomiting, or anorexia & 0 & $3(2.3)$ & $1(0.8)$ \\
\hline Diarrhea & 0 & $2(1.6)$ & 0 \\
\hline Gastrointestinal bleeding & 0 & 0 & 0 \\
\hline Rash & 0 & $2(1.6)$ & $1(0.8)$ \\
\hline Increased agitation & $2(0.5)$ & $2(1.6)$ & $3(2.3)$ \\
\hline Postural hypotension & 0 & 0 & $1(0.8)$ \\
\hline Fall & $1(0.2)$ & $2(1.6)$ & $2(1.5)$ \\
\hline Femoral fracture & $1(0.2)$ & $2(1.6)$ & 0 \\
\hline Stroke & $1(0.2)$ & $1(0.8)$ & 0 \\
\hline Myocardial infarction & 0 & $1(0.8)$ & 0 \\
\hline Urinary tract infection & 0 & $2(1.6)$ & $3(2.3)$ \\
\hline Chest infection & 0 & $1(0.8)$ & $1(0.8)$ \\
\hline Seizure & 0 & $2(1.6)$ & $3(2.3)$ \\
\hline Death & $4(0.9)$ & $3(2.3)$ & $4(3.1)$ \\
\hline
\end{tabular}

was 1.55 (95\% CI, 0.23 to 2.88), indicating greater cognitive deterioration in the placebo group $(\mathrm{P}=0.02)$. As with the SIB, the proportion of patients fully able to complete the examination was low (44\% in both groups).

\section{SENSITIVITY ANALYSES}

Results for the CMAI, NPI, NPI Caregiver Distress Scale, SIB, and SMMSE proved robust with different assumptions about departures from randomization policies and various other ways of handling missing data (see the Supplementary Appendix). For the CMAI, the results of the repeated-measures model (a linear mixed-effect model incorporating data from all four assessment points) were slightly in favor of the donepezil group $(0.29 ; 95 \% \mathrm{CI}$, -3.66 to 4.23 ) but were consistent with the results of the adjusted ANCOVA model (Table 2).

\section{ADVERSE EVENTS}

Adverse events were similar in the donepezil and placebo groups. Details of all reported adverse events are shown in Table 3.

\section{DISCUSSION}

This 12-week trial examined the effectiveness of donepezil for the treatment of clinically significant agitation in patients with Alzheimer's disease.
No significant treatment advantage was shown for donepezil as compared with placebo. The primary analysis, which was adjusted for baseline symptom severity, showed an estimated difference in the change from baseline of less than 0.1 point on the CMAI between the placebo and intervention groups. The confidence interval for the difference suggests that the study excluded a benefit of 4.5 points or more on a scale ranging from 29 to 203.

Although previous trials have indicated that cholinesterase-inhibitor therapy results in modest but significant improvement in the overall severity of neuropsychiatric symptoms in patients with mild levels of behavioral disturbance, this may be explained by improvements in symptoms other than agitation. For example, a study that examined individual items on the NPI in patients with Alzheimer's disease showed significant benefits for mood-related symptoms but not for agitation. ${ }^{28}$ Furthermore, in a trial in which rivastigmine was shown to have efficacy in the treatment of apathy, delusions, and hallucinations in patients who had dementia with Lewy bodies, there was no effect on the NPI measure for agitation. ${ }^{29}$

Like other studies examining the use of donepezil in the treatment of patients with severe Alzheimer's disease, ${ }^{30,31}$ our trial showed that on cognitive measures assessed by the SIB and SMMSE, there was a modest benefit from donepezil as compared with placebo.

The trial was conducted in a pragmatic manner, and the inclusion criteria were broad. Most of the patients in the study were nursing home residents with severe dementia and were thus representative of patients who present with difficult-to-manage behaviors, such as agitation. We chose agitation measured by the CMAI as the primary outcome because we believe this measure captures those behaviors that are most likely to lead to requests for drug treatment. However, agitation may not represent a homogenous clinical phenomenon, and this is a potential limitation of the trial. The generalizability of our findings is limited by the high proportion of women in our study and by the $35 \%$ of participants who did not proceed to randomization for a number of reasons, including successful completion of psychosocial treatment.

The effectiveness of second-generation antipsychotic drugs, which have become the mainstay of treatment for psychosis, agitation, and aggression in Alzheimer's disease, has been seriously questioned on the basis of the results of the Clinical 
Antipsychotic Trials of Intervention Effectiveness trial, which showed no significant advantage of these drugs over placebo. ${ }^{32}$ The results of our trial suggest that the cholinesterase inhibitors do not represent an effective alternative treatment for clinically significant agitation in patients with Alzheimer's disease.

Supported by grants from the MRC (G0100070) and the Alzheimer's Society. Risperidone was provided by Janssen, and donepezil by Eisai UK.

Dr. Howard reports serving on advisory boards for Pfizer/ Eisai, Janssen-Cilag, and Lundbeck and receiving lecture fees from Pfizer/Eisai. Dr. Ballard reports serving on advisory boards and receiving honoraria from Janssen-Cilag, Novartis, AstraZeneca, Pfizer/Eisai, and Lundbeck and research grants from Janssen-Cilag and Novartis. Dr. Brown reports receiving lecture fees from GlaxoSmithKline and grant support from
AstraZeneca. Dr. Burns reports receiving consulting fees from Pfizer/Eisai, Shire, and AstraZeneca, lecture fees from Shire, Novartis and Pfizer/Eisai, and research funding from Pfizer/ Eisai, Novartis, and Lundbeck. Dr. Bentham reports receiving consulting fees from TauRx Therapeutics and lecture fees from Pfizer/Eisai. Dr. Holmes reports receiving research grants from Pfizer/Eisai and serving on advisory boards for Pfizer/ Eisai and GlaxoSmithKline. Dr. Knapp reports serving on an advisory board for Eisai. Dr. Jones reports serving on advisory boards for Pfizer/Eisai and Lundbeck and receiving speaking fees from Pfizer/Eisai, Lundbeck, Shire, and Merz; he also reports that his department receives research grant funding from Pfizer/Eisai. Dr. O'Brien reports serving on advisory boards for Novartis and Lundbeck and receiving lecture fees from Pfizer/Eisai and Shire. Dr. Katona reports receiving speaking fees from Lundbeck and Shire and receiving research funding from Lundbeck. Dr. Wilcock reports serving as a consultant for Pfizer/Eisai. No other potential conflict of interest relevant to this article was reported.

\section{APPENDIX}

The following people or study centers participated in the CALM-AD Trial Group (all in the United Kingdom). Principal Investigators: R. Howard (chief investigator), Medical Research Council (MRC) Neurogeneration Research Center, Institute of Psychiatry, King's College London, London; C. Ballard, Wolfson Centre for Age Related Disease, King's College London, London; P. Bentham, Queen Elizabeth Psychiatric Hospital, Birmingham; R.G. Brown, Institute of Psychiatry, King's College London, London; R. Bullock, Victoria Hospital, Swindon; A. Burns, Division of Psychiatry, Manchester University, Manchester; C. Holmes, Memory Assessment and Research Centre, University of Southampton, Southampton; R. Jacoby, Department of Psychiatry, University of Oxford, Oxford; T. Johnson, MRC Biostatistics Unit, University of Cambridge Institute of Public Health, Cambridge; E. Juszczak, Centre for Statistics in Medicine, Wolfson College, Oxford; M. Knapp, Institute of Psychiatry, King's College London, London; J. Lindesay, Department of Health Sciences, University of Leicester, Leicester; J.T. O'Brien, Institute for Ageing and Health, Newcastle University, Newcastle. Trial Steering Committee: G. Wilcock (chair), Nuffield Department of Medicine, John Radcliffe Hospital, Oxford; R. Jones, Research Institute for the Care of the Elderly, Bath; C. Katona, Kent Institute of Medicine and Health, University of Kent, Kent; S. Sorensen, Alzheimer's Society UK, London; G. Cadwallader, MRC UK, London. Data Monitoring and Ethics Committee: B. Lawlor (chair), St. James's Hospital and Trinity College, Dublin; D. Ashby, Barts and the London, Queen Mary's School of Medicine, University of London, London; D. Findlay, Royal Dundee Liff Hospital, Dundee. Study Centers: Section of Old Age Psychiatry, Institute of Psychiatry, King's College London, London - J. DeCesare, M. Rodger, L. Beckford, L. Chambers, G. Vere, A. Snook, A. Langman, A. Oldershaw; Queen Elizabeth Psychiatric Hospital, Birmingham - R. Callaghan, J. Wright, A. Smythe; University of Leicester, Leicester - S. Baillon, P. Bradley, D. Malone, P. Wakefield; Wythenshawe Hospital, Manchester - D. Duignan, S. Karim; Institute for Ageing and Health, Newcastle - S. Douglas, L. Lee, R. Elvish, M. Krishnan, C. Partington, G. Hunter, M. Bhasin, A. Ravishankar; University of Oxford, Oxford — M. Clarke, L. Daniels; Memory Assessment and Research Centre, Southampton - C. Dean, E. Finbow; Kingshill Research Centre, Victoria Hospital, Swindon. MRC Clinical Trials Unit: S. Nally, S. Tebbs, A. Poland, D. Johnson. Centre for Statistics in Medicine, Oxford: J. Mollison.

\section{REFERENCES}

1. Howard R, Ballard C, O’Brien J, Burns A. Guidelines for the management of agitation in dementia. Int J Geriatr Psychiatry 2001;16:714-7.

2. Lyketsos CG, Steinberg M, Tschanz JT, Norton MC, Steffans DC, Breitner JCS. Mental and behavioural disturbances in dementia: findings from the Cache County Study on Memory in Aging. Am J Psychiatry 2000;157:708-14.

3. Margallo-Lana M, Swann A, O'Brien JT, et al. Prevalence and pharmacological management of behavioural and psychological symptoms amongst dementia sufferers living in care environments. Int J Geriatr Psychiatry 2001;16:39-44.

4. Rabins PV, Mace NL, Lucas MJ. The impact of dementia on the family. JAMA 1982;248:333-5.

5. Donaldson C, Tarrier N, Burns A. The impact of the symptoms of dementia on caregivers. Br J Psychiatry 1997;170:62-8.

6. Steele C, Rovner B, Chase GA, Folstein M. Psychiatric symptoms and nurs- ing home placement of patients with Alzheimer's disease. Am J Psychiatry 1990; 147:1049-51.

7. Ballard C, Waite J. The effectiveness of atypical antipsychotics for the treatment of aggression and psychosis in Alzheimer's disease. Cochrane Database Syst Rev 2006;1:CD003476.

8. Schneider LS, Dagerman K, Insell PS. Efficacy and adverse effects of atypical antipsychotics for dementia: meta-analysis of randomized, placebo-controlled trials. Am J Geriatr Psychiatry 2006;14:191-210. 9. Ballard C, Howard R. Neuroleptic drugs in dementia: benefits and harm. Nat Rev Neurosci 2006;7:492-500.

10. Cummings JL, Schneider L, Tariot PN, Kershaw PR, Yuan W. Reduction of behavioural disturbances and caregiver distress by galantamine in patients with Alzheimer's disease. Am J Psychiatry 2004;161: 532-8.

11. Cummings JL, Mega M, Gray K, Rosenburg-Thomas S, Carusi DA, Gorn- bein J. The Neuropsychiatric Inventory: comprehensive assessment of psychopathology in dementia. Neurology 1994; 44:2308-14.

12. Holmes C, Wilkinson D, Dean C, et al. The efficacy of donepezil in the treatment of neuropsychiatric symptoms in Alzheimer disease. Neurology 2004;63:214-9.

13. Trinh NH, Hoblyn J, Mohanty S, Yaffe K. Efficacy of cholinesterase inhibitors in the treatment of neuropsychiatric symptoms and functional impairment in Alzheimer disease: a meta-analysis. JAMA 2003;289:210-6.

14. Birks J. Cholinesterase inhibitors for Alzheimer's disease. Cochrane Database Syst Rev 2006;1:CD005593.

15. Herrmann N, Rabheru K, Wang J, Binder C. Galantamine treatment of problematic behaviour in Alzheimer disease: post-hoc analysis of pooled data from three large trials. Am J Geriatr Psychiatry 2005; 13:527-34.

16. Cohen-Mansfield J, Marx MS, Rosen- 
thal AS. A description of agitation in a nursing home. J Gerontol 1989;44:M77-M84.

17. Ballard C, Margallo-Lana M, Juszczak $\mathrm{E}$, et al. Quetiapine and rivastigmine and cognitive decline in Alzheimer's disease: randomised double blind placebo controlled trial. BMJ 2005;330:874-7.

18. Schneider LS, Pollock VE, Lyness SA. A meta-analysis of controlled trials of neuroleptic treatment in dementia. J Am Geriatr Soc 1990;38:553-63.

19. Medicines and Healthcare products Regulatory Agency. New advice issued on risperidone and olanzapine. London: MHRA, March 2004. (Accessed September 7, 2007, at http://www.mhra.gov.uk/ home/idcplg?IdcService=SS_GET_PAGE \&useSecondary $=$ true\&ssDocName= CON002047\&ssTargetNodeId $=389$.)

20. McKhann G, Drachman D, Folstein M, Katzman R, Price D, Stadlan EM. Clinical diagnosis of Alzheimer's disease: report of the NINCDS-ADRDA Work Group under the auspices of Department of Health and Human Services Task Force on Alzheimer's Disease. Neurology 1984; 34:939-44.

21. McKeith IG, Galasko D, Kosaka K, et al. Consensus guidelines for the clinical and pathologic diagnosis of dementia with Lewy bodies (DLB): report of the Consor- tium on DLB international workshop. Neurology 1996;47:1113-24.

22. Cohen-Mansfield J, Werner P. Management of verbally disruptive behaviors in nursing home residents. J Gerontol A Biol Med Sci 1997;56:M369-M377.

23. Wood S, Cummings JL, Hsu MA, et al The use of the neuropsychiatric inventory in nursing home residents: characterization and measurement. Am J Geriatr Psychiatry 2000;8:75-83.

24. Kaufer DI, Cummings JL, Christine D, et al. Assessing the impact of neuropsychiatric symptoms in Alzheimer's disease: the Neuropsychiatric Inventory Caregive Distress Scale. J Am Geriatr Soc 1998;46: 210-5

25. Saxton J, McGonigle-Gibson K, Swihart A, Miller M, Boller F. Assessment of severely impaired patients: description and validation of a new neuropsychological test battery. Psychol Assess 1990;2:298303.

26. Molloy DW, Alemayehu E, Roberts R. Reliability of a Standardized Mini-Mental State Examination compared with the traditional Mini-Mental State Examination. Am J Psychiatry 1991;148:102-5.

27. Schneider LS, Olin JT, Doody RS, et al. Validity and reliability of the Alzheimer's Disease Co-operative Study-Clinical
Global Impression of Change. Alzheimer Dis Assoc Disord 1997;11:Suppl 2:S22S32.

28. Gauthier S, Feldman H, Hecker J, et al. Efficacy of donepezil on behavioural symptoms in patients with moderate to severe Alzheimer's disease. Int Psychogeriatr 2002;14:389-404.

29. McKeith I, Del Ser T, Spano PF, et al. Efficacy of rivastigmine in dementia with Lewy bodies: a randomised, double-blind, placebo-controlled international study. Lancet 2000;356:2031-6.

30. Feldman H, Gautier S, Hecker J, Vellas B, Subbiah P, Whalen E. A 24-week randomized, double-blind study of donepezil in moderate-to-severe Alzheimer's disease. Neurology 2001;57:613-20. [Erratum, Neurology 2001;57:2153.]

31. Winblad B, Kilander L, Eriksson S, et al. Donepezil in patients with severe Alzheimer's disease: double-blind, parallelgroup, placebo-controlled study. Lancet 2006;367:1057-65. [Errata, Lancet 2006;367: 1980, 2006;368:1650.]

32. Schneider LS, Tariot PN, Dagerman KS, et al. Effectiveness of atypical antipsychotic drugs in patients with Alzheimer's disease. N Engl J Med 2006;355: 1525-38.

Copyright (c) 2007 Massachusetts Medical Society.

APPLY FOR JOBS ELECTRONICALLY AT THE NEJM CAREERCENTER Physicians registered at the NEJM CareerCenter can apply for jobs electronically using their own cover letters and CVs. You can keep track of your job-application history with a personal account that is created when you register with the CareerCenter and apply for jobs seen online at our Web site. Visit www.nejmjobs.org for more information. 